Article

\title{
Impact of the Fukushima Nuclear Accident on Belief in Rumors: The Role of Risk Perception and Communication
}

\author{
Seoyong $\operatorname{Kim}^{1}$ and Sunhee $\operatorname{Kim}^{2, *}$ \\ 1 Department of Public Administration, Ajou University, Worldcup-ro, Suwon 16499, Korea; \\ seoyongkim@ajou.ac.kr \\ 2 Department of Public Administration, Seowon University, Musimseoro, Cheongju 28674, \\ Chungbuk 361-742, Korea \\ * Correspondence: shkim7675@hanmail.net; Tel.: +82-043-299-8616
}

Received: 14 October 2017; Accepted: 22 November 2017; Published: 27 November 2017

\begin{abstract}
Rumors about nuclear power energy and its risks in terms of technology are common. However, these rumors are sometimes exaggerated and not true. Our research question is what factors and variables have influence the rumors related to the Fukushima nuclear accident. We analyzed data collected through social survey $(n=1572)$. To measure the dependent variable, we asked respondents whether rumors related to the Fukushima nuclear accident were true or false, and the degree to which they trusted such rumors. We measured three factors in determining belief in rumors: psychometric paradigm, communication, and risk perception. We then analyzed the direct impact of these three factors on belief in rumors and the indirect moderating effect of perceived risk of the Fukushima nuclear accident on the relationship between psychometric factors and belief in rumors. Results show that in the communication factors, source credibility decreases belief in rumors whereas usefulness of information and receiver's ability increase it. All the psychometric variables have significant impacts on belief in rumors. Perceived benefit, trust, and knowledge decrease belief in rumors, and perceived risk and stigma increase it. Finally, the perceived risk of Fukushima accident plays a role of moderators between psychometric paradigm and belief in rumors.
\end{abstract}

Keywords: Fukushima accident; belief in rumor; risk perception

\section{Introduction}

The Fukushima nuclear accident, which occurred in Japan in March 2011, changed people's attitudes toward nuclear power energy. Support for nuclear power has decreased in Japan as well as other countries. After examining the effect of the Fukushima disaster on public acceptance of nuclear energy in 42 countries, Kim et al. [1] reported that even people with a positive experience of nuclear power generation took on a considerably more negative attitude after the Fukushima disaster.

As this disaster significantly changed the public's perceived risk of nuclear power, public acceptance has significantly decreased [2]. Tsujikawa et al. [3] showed that public support for nuclear power decreased more in Japan than in other countries, with supportive opinions plummeting from $50 \%$ before the Fukushima accident to $37 \%$ after the event, and opposing opinions rising from $32 \%$ to $42 \%$. Similar trends were observed in other countries. In Switzerland, Visschers and Siegrist [4] conducted a longitudinal survey study $(n=790)$ five months before and immediately after the Fukushima accident. They found that after the accident, acceptance of nuclear power energy was lower and public perception of this form of energy generation was more negative. After the Fukushima disaster, even those that had previously benefited from nuclear energy became considerably more negative in their attitude toward it [1]. 
These attitude shifts toward nuclear power from positive to negative resulted from both "true facts" directly related to the Fukushima accident and "false facts", namely rumors. When a large-scale disaster occurs, people try to collect as much information on it as possible [5], and in this large amount of data, there is often both true or confirmed information as well as false or unfiltered information [6]. After the 2011 Fukushima accident, both truthful information and rumors based on false information was disseminated globally. In Japan, these rumors became issues in legal cases. In July 2016, a Japanese court ordered Tokyo Electric Power Co., which operated the nuclear power station in Fukushima, to compensate a golf course operator for revenue lost because of "false rumors" related to the accident at the nuclear power plant [7]. Rumors related to the Fukushima nuclear accident rapidly spread across the country border, and, once spread, they remained in people's minds for a long time, sometimes exacerbating the disaster situation [8].

These rumors negatively affected the acceptance of nuclear power also in Korea, the nearest country to Japan. In 2013, two years after the Fukushima accident, the people in Korea were still subject to many rumors related to the disaster. Chosun Ilbo reported that seven specific rumors turned out to be false [9], including the following: "more than $70 \%$ of the territory of Japan was contaminated by cesium and half the Japanese archipelago was already contaminated by a high concentration of radioactivity". "To control information pertaining to radioactivity, the Japanese government prohibited the measurement of radiation by law". "The volume of radioactivity outflow during the Fukushima nuclear accident was 11 times larger than that in the Chernobyl nuclear accident". "The Ambassador to Japan from Australia and the Canadian embassy stopped issuing visas to the Japanese people". "Foods contaminated by radioactivity not eaten in Japan were imported into South Korea". Moreover, the Korea Food Drug Agency (KFDA) explained that the rumors about contaminated seafood were not true. On 2 August 2013, the Prime Minister announced that to control rumors related to the Fukushima accident, the government would trace and punish those who distributed false speculations. Even though many rumors have been pointed out as false information, many people still believe them to be true.

Rumors have both negative and positive functions. In positive terms, they sometimes stimulate discussions of social issues. In dissolving the suspicion embedded in rumors, better social discourses are formed, contributing to the resolution social conflict. On the other hand, if rumors distort social facts, they produce suspicion and distrust, thus reproducing social conflict.

Although previous research successfully defined the construct of rumor, there were unproven themes Aspects uncovered in rumor studies include the determinants of belief in rumors. Compared to the transmission or dissemination of rumors, few studies empirically analyze belief in rumors and its determinants. In this paper, we identify the factors that explain the belief in rumors related to nuclear power energy issues. We measured people's attitudes toward six rumors that spread in Korea after the Fukushima accident, which we set as dependent variables. For independent variables, we focused on the following three factors: the psychometric paradigm, communication, and perceived risk of the Fukushima accident. The first included perceived risk/benefit, trust, stigma, and knowledge. The second factor concerns source credibility, the quantity and usefulness of information, and receivers' ability and involvement.

Our research question is what factors and variables have influence the rumors. Our hypothesis was that in addition to the risk perception of the Fukushima accident, variables in communication and psychometric factors also influence belief in rumor. Moreover, risk perception of Fukushima nuclear accident moderates the relationships between communication/psychometric factors and belief in rumor. Our research will contribute to providing a more persuasive theoretical model for belief in rumors by combining communication and psychometric paradigm. 


\section{Literature Review}

\subsection{Rumor Studies}

Rumor studies have a long research history, which began with the analysis of thousands of rumors during World War II. Initial researches focused on the damaged morale and national safety issues caused by rumors intentionally disseminated by the enemy. In "A Psychology of Rumor", a seminal work in the field published in 1944, Robert Knapp [10] defined "rumor as a proposition for belief in a topical reference disseminated without official verification" (p. 22). Defined as such, rumor is a specific case of informal social communication, including myth, legend, and current humor. It is distinguished from myth and legend by its emphasis on the topical. Where humor is designed to provoke laughter, rumor begs for belief. Furthermore, rumor is defined as the unverified and instrumentally relevant information statements in circulation that arise in contexts of ambiguity, danger, or potential threat and that function to help people make sense of and manage risk [11] (p. 13). Similarly, rumors are propositions or allegations colored by various shades of doubt, because they are not accompanied by corroborative evidence [12] (p. 4).

Rumors are related to various psychological factors. In their seminal research, Allport and Postman [13,14] suggested a basic law of rumor: $R=i \times a$. This indicates that rumor strength (R) varies according to information on the subject to the individual concerned (i) multiplied by the ambiguity of the evidence pertaining to the topic at hand (a). They postulated that the occurrence of rumors depends on the importance of issues for individuals and the degree of ambiguity underlying the rumor. Moreover, Rosnow [15] suggested that the generation and transmission of rumors result from an optimal combination of personal anxiety, general uncertainty, credulity, and outcome-relevant involvement.

Many rumor studies focus on psychological dimensions and dismiss macro-structural factors such as context or communication. Recently, rumor studies have shifted focus to the structural dimension of rumors. DiFonzo and Bordia [16] highlighted three macro dimensions of social discourse: context (the situation and/or psychological need out of which discourse arises), function (what people are trying to accomplish by becoming emerged in the discourse), and content (the types of statements uttered) (p. 213). Of these three dimensions, context concerns causal factors that influence or produce the rumor. According to DiFonzo and Bordia [16], rumors arise from situational contexts that are ambiguous, threatening, or potentially threatening, wherein people feel a psychological need for understanding or security (p. 203). As such, in terms of threat, context is applicable to the Fukushima nuclear accidents. To increase the practical implications of theoretical rumor studies, empirical studies on rumors related to the Fukushima nuclear disaster are needed, but few have been conducted [6].

What factors instigate belief in rumors? Our study focused on risk perception and communication factors, as these were the dominant paradigms in previous researches on risk perception and acceptance of nuclear power energy.

\subsection{Risk Perception Paradigm vs. Risk Communication Model}

Paul Slovic and his colleagues proposed the psychometric paradigm (i.e., the risk perception paradigm) in which risk is not an objective attribute but a subjective construct [17]. Therefore, the degree of risk depends on people's subjective judgment. This paradigm produced a "cognitive map" of hazards, identifying the characteristics of risk as having inherent attributes. In a seminal work on the psychometric paradigm, Fischhoff et al. [18] identified characteristics that increase perceived risk, one of which refers to dread and the unknown. The first invokes feelings of terror, catastrophe, inequality, and the uncontrolled. An unknown risk is new to people and science. Based on factor analysis, Slovic et al. [19] found that the 18 characteristics of risk could be reduced to three factors, namely dread, the unknown, and exposure. Moreover, they reported that a higher perceived risk and desire for regulation were related to items rated high on the dread factor, regardless of the objective, expected number of fatalities. 
The risk perception paradigm well explains the paradox of risk in which individual demonstrates higher perceived risk for risky events, even when their probability of occurrence is low. However, the risk perception paradigm dismissed the macro objective structure. Wildavsky [20] explained that the psychometric paradigm explains the differences within, not between, individual effects. This means that the paradigm does not consider the more contextual factors influencing individuals' perception.

Recently, a more advanced version of the risk perception paradigm focused on the causal relationships in specific risky objects, such as genetically modified organisms (GMO) [21], nanotechnology [22], and nuclear power energy [11]. In these studies, the main question prioritized those factors that increase or decrease the acceptance of risk objects, including perceived benefit, perceived risk, trust, stigma, and knowledge [1,4].

The risk communication paradigm is also important in risk studies. Generally, the traditional approach to risk communication is based on the communication model, which focuses on information transfer between sources, transmitters, and receivers. A message is composed by the communication source and sent to a transmitter. The transmitters decode or recode the message and send it to receivers, who decode the message and decipher its meaning [23]. This model was originally developed by Shannon and Weaver in 1949 [24], and it is still used today to explain communication in social events and disasters.

Recently, more advanced studies applying traditional communication have been conducted. For example, Kasperson et al. [25] applied the communication model to risk studies, conceptualizing the social amplification of risk model. They suggested that information processes as well as institutional structure, social group behavior, and individual responses shape the social experience of risk as they elicit risk consequences. In this model, the socially amplified communication process follows a long path: risk event $\rightarrow$ event characteristics $\rightarrow$ information flow $\rightarrow$ interpretation and response $\rightarrow$ spread of impact $\rightarrow$ type of impact. This structural model demonstrates the overall pattern of communication, delineating the participants in and components of the communication process.

We proposed a comprehensive model that integrates the communication model and the psychometric theory. Why is such integration necessary? It is necessary because each theory on its own has weakness. First, while the communication model stresses receiver, message, and source, it fails to fully specify receiver's perception, which can be well explained by variables in the psychometric paradigm. On the other hand, the psychometric paradigm has the strength in explaining the variance of individual perception. However, it does not consider the structure and context of communication that influence the receiver's perception. The communication model provides an effective construct to identify such structure and context by focusing not only on actor but also other factors in the communication process.

Even though the risk perception paradigm and the risk communication model are similar in theoretical argument, they do differ, as shown in Table 1. 
Table 1. Comparison of risk perception paradigm and risk communication model.

\begin{tabular}{|c|c|c|}
\hline & Risk Perception Paradigm & Risk Communication Model \\
\hline Discipline & Psychology & $\begin{array}{l}\text { Information } \\
\text { theory, communication }\end{array}$ \\
\hline Key variable & $\begin{array}{l}\text { - Perceived benefit, perceived risk, } \\
\text { stigma, trust, and knowledge }\end{array}$ & $\begin{array}{l}\text { Receiver, message } \\
\text { (information), source }\end{array}$ \\
\hline $\begin{array}{l}\text { Assumption about mode of } \\
\text { judgment }\end{array}$ & Independent judgment & Interdependent judgment \\
\hline Method & $\begin{array}{l}\text { - Quantitative method, } \\
\text { mainly survey }\end{array}$ & $\begin{array}{l}\text { Qualitative and } \\
\text { quantitative methods }\end{array}$ \\
\hline Strength & $\begin{array}{ll}\text { - } & \text { Causal explanation } \\
\text { - } & \text { Explanation power in } \\
& \text { risk judgment }\end{array}$ & 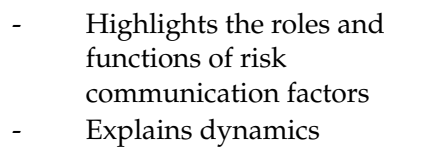 \\
\hline Weakness & $\begin{array}{l}\text { - } \quad \begin{array}{l}\text { Dismisses the context } \\
\text { - }\end{array} \quad \begin{array}{l}\text { Poor in explaining } \\
\text { perception change }\end{array}\end{array}$ & $\begin{array}{ll}\text { - } & \text { Limited generalization } \\
\text { - } & \text { Oversimplifies the complex } \\
\text { communication process }\end{array}$ \\
\hline
\end{tabular}

Note: Revised from Kim et al. [26].

\subsection{Risk Communication Model}

Among the variables emphasized by the communication model, our research focused on source credibility, the quantity and quality of information, and the receiver's involvement and ability.

First, source credibility is a key factor in rumor judgment and refers to interpersonal trust, which relates to the perceived presence or absence of particular traits in the source [27] (p. 344). It is expected that a more credible source will reduce belief in rumors. After analyzing 1089 rumors from World War II, Knapp [10] showed a relationship between flourishing rumors and a credible source that portrayed validity. Porter's study [28] demonstrated strong relationships between the credibility of the rumor communicator and belief in negative rumors, and Liang et al. [29] showed that source credibility increases college students' belief in internet rumors related to consumption.

However, the source effect frequently depends on the source object. Trumbo and McComas [27] identified the effects of source credibility, finding that higher credibility of industry and the state elicits lower risk perception, whereas high credibility of citizen groups increases risk perception. Moreover, trust in the source decreases belief in rumors, while the credibility of the rumors facilitates it. As our study measured the former, we proposed in Hypothesis 1 that source credibility would reduce belief in rumors.

Second, the amount of information changed attitudes toward nuclear power. Rumors usually depend on the quantity of information, which conveys false or true contents. Certainly, rumors thrive on a lack of news. The volume of negative information usually facilitates belief in rumors [13]. As such, a high proportion of negative information in consumer reviews facilitates a conformity effect [30].

Third, both the quantity and quality of information matter. A high-quality message is fundamental in persuasion: the higher the quality of a message, the more persuasive it is [31]. Different qualities have different impacts on belief in rumors. As such, various aspects of qualitative information exist, such as usefulness, exactness, and vividness. Our study focused on the usefulness of information. Rumors are information statements in circulation, which are perceived as useful by participants [16]. 
Most people believed the rumor in question because they found it useful to do so [32]. Negative rumors are a substitution for positive information. Generally, a rumor thrives when knowledge or useful information is lacking. Therefore, useful information for receivers decreases belief in rumors. Our measure of the usefulness of information focused on whether it contributes to the understanding of issues of nuclear power energy. Thus, our Hypothesis 1 was that increased understanding through useful information would decrease dependence on the rumor.

Fourth, receivers' involvement is a means of persuasion and judgment. The degree of involvement or relevance increases the engagement in judgment. In rumor studies, relevance is one variable of focus. Recently, Rosnow and Kimmel [33] (p. 122) defined rumor as an unverified proposition of belief that bears topical relevance for persons actively involved in its dissemination. Allport and Postman [10] postulated that "the amount of rumor circulation will vary with the importance of the subject to the individuals concerned" (p. 34). Petty and Cacciopo [34] showed that if messages obtained from the media have high personal relevance, they are judged with more scrutiny. Moreover, an empirical study by Liang et al. [29] demonstrated that involvement reduced belief in rumors. Our analysis focused on issue involvement. According to Petty and Cacioppo [35], issue involvement concerns the extent to which the attitudinal issue under consideration is of personal importance. They explained that more issue involvement was associated with resistance to persuasion because it was related to an extended "latitude of rejection" (the attitudinal positions that a person finds unacceptable) (p. 1916).

Fifth, individuals' ability related to information affects their choices regarding informationprocessing methods [36]. For example, lower cognitive ability leads to heuristic, not systematic information processing [37]. This implies that a lower ability increases belief in rumors.

Hypothesis 1. Source credibility, usefulness of information, and the receiver's involvement and ability decrease belief in rumors, whereas the quantity of negative information increases it.

\subsection{Psychometric Paradigm}

Rumor studies implicitly mention risk factors. Rumors spread in insecure, uncertain, and ambiguous situations. For example, DiFonzo and Bordia [16] argued that rumors arise in situational contexts that are threatening or potentially threatening and when people feel an acute need for security (p. 213). The threat may be tangible, when one's life is in danger. Uncertainty and anxiety naturally occur in ambiguous situations involving dreaded events. Uncertainty may lead to anxiety through a reduced sense of control [11]. Disaster always accompanies this insecurity, uncertainty, feeling threatened, and anxiety, all of which facilitate belief in rumors and are applicable in the Fukushima accident. Which factors facilitate belief in rumors about the Fukushima accident? We set the five variables of the psychometric paradigm-perceived risk and benefit, knowledge, trust, and stigma-because these have been extensively investigated in risk studies on nuclear power energy. Perceived benefit [4], trust [4], and knowledge [38,39] increase acceptance of nuclear power energy, whereas perceived risk [2-4] and stigma [31,32] decrease it. We assumed that such structural relationships between five variables and acceptance applied to belief in rumor. In the section below, we provide a hypothesis by connecting such five independent variables with belief in rumors.

First, perceived benefit and risk are key variables in determining the acceptance of nuclear power. Perceived risk and benefit demonstrate contrasting effects on the acceptance of nuclear power energy. The first decreases positive attitudes toward any object of nuclear power, while the second increases it. According to Visschers and Siegrist [4], in Switzerland, the perceived benefit and risk determined the acceptance of nuclear power stations both before and after the Fukushima accident. Moreover, these two variables have a larger explanatory power: the perceived benefits before Fukushima correlated with perceived benefits after the accident. In Japan, Tsujkawa et al. [3] found that the perceived benefit had a weaker positive impact on public acceptance. Dread and fear might amplify rumors, while the positive benefits discount the negative effects of eroded belief. 
Second, knowledge plays a role in increasing the acceptance of nuclear power energy. According to Kuklinski et al. [38], more knowledge is less likely to oppose the operation and construction of nuclear power stations. Brown and White [39] indicated that the public does not understand the risk because they generally lack knowledge of nuclear power. Such previous studies emphasize that knowledge plays the role of enlightenment, decreasing biased or false beliefs. The deficit model is the most well-known model for explaining the role of knowledge in judgment. According to Dickson [40], the deficit model argues that a lack of adequate knowledge about science mainly influences public skepticism toward modern science and technology. If given sufficient information about science and technology to overcome this lack of knowledge, the public could change its mind and make a better decision. Similarly, we assume that more knowledge will correct false or inaccurate beliefs, in other words, rumors.

Third, trust is a significant variable regarding the acceptance of nuclear power. This directly affects the perception of nuclear power energy. Based on a longitudinal study $(n=790)$ in Switzerland, Visschers and Siegrist [4] showed that trust affects benefit and risk perceptions and that trust before a disaster relates to trust after the Fukushima accident. In Japan, Tsujkawa et al. [3] indicated that after the Fukushima accident, trust in managing bodies, which depends on a pro-environmental orientation, influenced perceived risk. Moreover, Siegrist and Cvetkovich [41] verified that the role of trust depends on knowledge. When an individual lacks knowledge of hazards, social trust in the authorities managing the hazard influences the perceived risk and benefit. Our study measures trust in government, which should decrease belief in rumors.

Fourth, stigma refers to the negative affective image of the risk object. The affective values of these negative images predict the negative attitudes and behaviors related to nuclear power. Slovic et al. [42] highlighted that stigmatized nuclear images associated with Las Vegas and the State of Nevada might have adverse economic effects. Moreover, based on survey data, Peter and Slovic [43] demonstrated that affect based on a negative image is a significant factor in perceived risk. Logically, the negativity of a stigma and feeling might increase belief in rumors.

Based on previous researches, perceived risk and stigma increase negative attitudes toward nuclear power, while perceived benefit, trust, and knowledge increase positive attitudes. These directions can be applied to belief in rumors related to the Fukushima accident. Rumors about nuclear power energy have negative connotations, which convey less trust/benefit/knowledge and more risk/stigma. Therefore, negative causal variables - that is, perceived risk and stigma-to reduce the acceptance of nuclear power might increase belief in negative rumors, while positive variables-perceived benefit, trust, and knowledge-decrease it. Hence, we suggest the following hypothesis.

Hypothesis 2. Perceived risk and stigma increase belief in rumors, whereas perceived benefit, trust, and knowledge decrease it.

\subsection{Risk Perception of Fukushima Nuclear Accident}

After the Fukushima nuclear accident, many studies found that the accident negatively affected attitudes toward nuclear power energy $[1,3,4]$. If there was a negative turn toward nuclear power, it can be logically deducted that the Fukushima accident increased both belief in rumors and other kinds of perception.

First, the Fukushima accident might have increased belief in rumors. Allport and Postman [13] suggested the basic law of rumor (rumor transmission = importance of the rumor multiplied by the ambiguity of the situation), which highlights the relationships between the importance of and uncertainty in rumor transmission. The Fukushima accident gave rise to extreme uncertainty, and many negative rumors emerged after this large-scale disaster. In a classic study on rumor by Prasad [44], when the great earthquake occurred on 15 January 1934, in Bihar, India, many rumors spread in an 
unprecedented panic. He noted that a typical situation exacerbating the spread of popular rumors is one that (a) creates an emotional disturbance, (b) is uncommon and unfamiliar, (c) contains many aspects unknown to the individuals affected, (d) contains several unverifiable factors, and (e) is of group interest (p. 5). These situational characteristics match those of the Fukushima nuclear accident. Therefore, as the perceived risk of the Fukushima accident increases, so too does belief in rumors.

Second, several studies $[1,3,4,45,46]$ indicated that the Fukushima nuclear accident influenced perceptions of perceived risk or benefit, trust, and stigma. Yamamura [46] showed that experience of a technological disaster, not a natural one, affected the perceived risk of nuclear accidents after the Fukushima nuclear disaster. Visschers and Siegrist [4] discovered the negative turn of trust toward nuclear power after the Fukushima accident. Also identified was a decrease in trust in nuclear and environmental organizations as well as pronuclear attitudes [46].

The abovementioned findings suggest that the Fukushima accident might have increased belief in rumors and shifted perceptions. These two effects suggest the possible moderating role of risk perception in the Fukushima accident. Therefore, we hypothesized that the perceived risk of the Fukushima accident moderates the relationship between perception (perceived risk and benefit, trust, knowledge, and stigma) and belief in rumors.

Hypothesis 3. The Fukushima accident increases belief in rumors and moderated the relationship between perception (perceived risk and benefit, trust, knowledge, and stigma) and belief in rumors.

\section{Data and Measures}

Our study was based on survey data $(n=1572)$. To ensure the random sample of the Korean people, survey respondents were selected through a proportional quota sampling method. Data was collected by web survey, from 13 to 21 April 2016. To meet the quota in gender, age and region, 17,578 e-mail survey questionnaires in total were distributed through web survey management system. Of these, 5983 opened the e-mail, 2569 participated the survey, and 1572 respondents completed it ( $26.3 \%$ response rate).

Respondents consisted of 813 (51.7\%) males and 759 (48.3\%) females. Of the sample, $15.0 \%$ $(n=236)$ were high school graduates or below, $70.5 \%(n=1108)$ were attending university, and $14.5 \%$ $(n=228)$ were graduates. The mean age was 43.26 years.

Our study used the Fukushima accident as a case for theory building. To build a theory by case studies, it is necessary to first choose an appropriate case for theory testing. In the hypothesis-testing contributions by case studies, Eckstein [47] emphasized selecting a crucial case based on most/least likely case designs. The Fukushima accident was the best case for testing the theory of belief in rumors since there were various rumors not proved surrounding the disaster. Second, for generalizing the findings from case studies, a hypothesis or proposition is needed for testing the theory. Accordingly, after constructing our hypotheses from the communication model and the psychometric model, we tested them. Yin [48] suggested analytic generalization, in which a previously developed proposition is used as a template with which to compare the empirical results of the case study. Among various types of case studies, we adopted the type of theory-confirming and theory-infirming case study, which analyzes a single case within the framework of established generalization. If the case study is of the theory-confirming type, it strengthens the proposition in question (p. 65) [49].

Belief in rumors refers to the confidence of people in the truth of a rumor [11]. We measured belief in rumors by compositing two variables: multiplying the number of true/false statements as related to six specific rumors by the degree of confidence in the general statement related to rumors.

About true/false statements, we provided respondents with six rumors related to the Fukushima accident. One example was that when the Fukushima nuclear accident occurred, the Canadian and Australian embassies stopped issuing visas to Japanese people. All six rumors were false. We asked 
respondents to judge whether the rumors were true or false and to indicate their response on a five-point scale (" $1=$ definitely true" vs. " $5=$ definitely false").

Regarding the general statements about rumors, we asked respondents to provide their personal opinions about two statements about rumors: "I think that the rumors about nuclear power on the Internet are almost all true" and "Most negative rumors about nuclear power, which we see on the Internet, are factually true". Responses were measured on a five-point scale, where " $1=$ strongly disagree" and " 5 = strongly agree".

Other measures of the independent variables are shown in Table 2. Except stigma, all measures used a five-point scale where $1=$ strongly disagree and $5=$ strongly agree. Stigma was measured by evaluating five pairs of affect adjectives $(1=$ clean and $5=$ dirty). After thinking about nuclear power, respondents read the adjectives and checked the points closest to their thoughts. We composited the scale by averaging related items. Before compositing the scale, we tested reliability based on Cronbach's $\alpha$. Cronbach's $\alpha$ for all measures was higher than 60 .

Table 2. Measures and reliability.

\begin{tabular}{|c|c|c|}
\hline Variable & Item & Reliability \\
\hline Perceived Benefit & $\begin{array}{l}\text { Nuclear power energy will contribute to solving current climate change } \\
\text { problems. } \\
\text { Nuclear power energy will solve environmental problems. } \\
\text { Nuclear power energy is cheap and provides stability. } \\
\text { Nuclear power contributes to economic development. }\end{array}$ & 0.835 \\
\hline Perceived Risk & $\begin{array}{l}\text { I personally feel threatened by nuclear power. } \\
\text { Nuclear power produces hazardous waste. } \\
\text { Nuclear power is harmful to people's health. } \\
\text { Nuclear power stations are dangerous. } \\
\text { The nuclear power stations in our country operate safely }{ }^{\circledR} \text {. }\end{array}$ & 0.781 \\
\hline Knowledge & $\begin{array}{l}\text { I know the organization that regulates the safety of nuclear power. } \\
\text { I know to some extent the law regarding safety regulations on nuclear power. } \\
\text { I can explain the issues pertaining to nuclear power to other people. } \\
\text { I know the policy on and issues related to nuclear power. }\end{array}$ & 0.893 \\
\hline Stigma & $\begin{array}{l}\text { bright } \leftrightarrow \text { dark } \\
\text { clean } \leftrightarrow \text { dirty } \\
\text { progressive } \leftrightarrow \text { retrogressive } \\
\text { good } \leftrightarrow \text { bad } \\
\text { positive } \leftrightarrow \text { negative } \\
\text { warm } \leftrightarrow \text { cold } \\
\text { hopeful } \leftrightarrow \text { pessimistic } \\
\text { friendly } \leftrightarrow \text { unfriendly }\end{array}$ & 0.910 \\
\hline Quantity of Information & $\begin{array}{l}\text { I read a lot of information related to nuclear energy on the Internet. } \\
\text { I have received a lot of information related to nuclear energy on the Internet. }\end{array}$ & 0.895 \\
\hline Source Credibility & $\begin{array}{l}\text { The government provides (1) trustworthy, (2) exact, (3) fact-based objective, (4) } \\
\text { fair, (5) valid, (6) expertise) information on nuclear safety and regulation. }\end{array}$ & 0.954 \\
\hline $\begin{array}{l}\text { Usefulness of } \\
\text { Information }\end{array}$ & $\begin{array}{l}\text { Information gathered from the Internet is helpful in understanding issues } \\
\text { pertaining to nuclear power. } \\
\text { Information about nuclear power obtained from the Internet helps in } \\
\text { understanding the main problem of nuclear power. }\end{array}$ & 0.861 \\
\hline Receiver's Involvement & $\begin{array}{l}\text { I am interested in nuclear-related disputes on the Internet. } \\
\text { I am usually engrossed in debates on nuclear issues on the Internet. }\end{array}$ & 0.865 \\
\hline Receiver's Ability & $\begin{array}{l}\text { I have the ability to transmit information about nuclear power through the } \\
\text { Internet. } \\
\text { I can transfer information related to nuclear power energy as I want. }\end{array}$ & 0.096 \\
\hline
\end{tabular}

\section{Analysis}

To obtain descriptive statistics, we calculated the correlation coefficient, mean, and standard deviation (SD), as shown in Table 3. 
Table 3. Correlation, mean, and SD.

\begin{tabular}{|c|c|c|c|c|c|c|c|c|c|c|c|c|c|}
\hline & & 1 & 2 & 3 & 4 & 5 & 6 & 7 & 8 & 9 & 10 & 11 & 12 \\
\hline \multicolumn{2}{|c|}{$\begin{array}{l}\text { 1. Belief in Rumors } \\
\text { 2. Fukushima accident }\end{array}$} & $\begin{array}{c}1 \\
0.409^{* * *}\end{array}$ & 1 & & & & & & & & & & \\
\hline $\begin{array}{l}\text { Communication } \\
\text { factor }\end{array}$ & $\begin{array}{l}\text { 3. Source credibility } \\
\text { 4. Quantity of information } \\
\text { 5. Usefulness of information } \\
\text { 6. Receiver's involvement } \\
\text { 7. Receiver's ability }\end{array}$ & $\begin{array}{c}-0.297^{* * *} \\
0.275^{* * *} \\
0.076^{* * * *} \\
0.082^{* * *} \\
0.049^{*}\end{array}$ & $\begin{array}{l}-0.215^{* * *} \\
0.206^{* * *} \\
0.077^{* * *} \\
0.121^{* * * *} \\
0.017\end{array}$ & $\begin{array}{c}1 \\
-0.363^{* * *} \\
0.099^{* * *} \\
0.003 \\
0.036\end{array}$ & $\begin{array}{c}1 \\
-0.026 \\
0.076^{* * * *} \\
0.041\end{array}$ & $\begin{array}{c}1 \\
0.257^{* * *} \\
0.389^{* * *}\end{array}$ & $\begin{array}{c}1 \\
0.376^{* * *}\end{array}$ & 1 & & & & & \\
\hline \multirow[t]{2}{*}{ Psychometric factor } & $\begin{array}{l}\text { 8. Perceived benefit } \\
\text { 9. Perceived risk } \\
\text { 10. Trust } \\
\text { 11 Knowledge } \\
\text { 12. Emotion }\end{array}$ & $\begin{array}{c}-0.322^{* * *} \\
0.367^{* * *} \\
-0.316^{* * *} \\
-0.114^{* * *} \\
0.333^{* * *}\end{array}$ & $\begin{array}{c}-0.178^{* * *} \\
0.329^{* * *} \\
-0.192^{* * *} \\
-00.035 \\
0.24^{* * *}\end{array}$ & $\begin{array}{c}0.398^{* * *} \\
-0.288^{* * *} \\
0.676^{* * *} \\
0.123^{* * *} \\
-0.409^{* * *}\end{array}$ & $\begin{array}{c}-0.474^{* * * *} \\
0.357^{* * *} \\
-0.361^{* * *} \\
-0.026 \\
0.875^{* * *}\end{array}$ & $\begin{array}{c}0.002 \\
0.074 * * * \\
0.04 \\
0.189 * * * \\
-0.033\end{array}$ & $\begin{array}{c}-0.006 \\
0.106 * * * \\
-0.012 \\
0.368^{* * *} \\
0.02\end{array}$ & $\begin{array}{c}-0.017 \\
0.009 \\
0.029 \\
0.351 * * * \\
-0.002\end{array}$ & $\begin{array}{c}1 \\
-0.34^{* * *} \\
0.403^{* * *} \\
0.147^{* * *} \\
-0.536^{* * *}\end{array}$ & $\begin{array}{c}1 \\
-0.351^{* * *} \\
-0.06^{* *} \\
0.429^{* * *}\end{array}$ & $\begin{array}{c}1 \\
0.137^{* * * *} \\
-0.43^{* * *}\end{array}$ & $\begin{array}{c}1 \\
-0.108^{* * *}\end{array}$ & 1 \\
\hline & $\begin{array}{l}\text { Mean } \\
\text { S.D. }\end{array}$ & $\begin{array}{c}9.13 \\
3.683\end{array}$ & $\begin{array}{l}3.787 \\
0.904\end{array}$ & $\begin{array}{l}2.947 \\
0.738\end{array}$ & $\begin{array}{l}2.922 \\
0.822\end{array}$ & $\begin{array}{l}3.198 \\
0.683\end{array}$ & $\begin{array}{l}2.617 \\
0.818\end{array}$ & $\begin{array}{l}2.747 \\
0.864\end{array}$ & $\begin{array}{l}3.354 \\
0.899\end{array}$ & $\begin{array}{l}3.799 \\
0.787\end{array}$ & $\begin{array}{c}2.64 \\
1.064\end{array}$ & $\begin{array}{l}2.341 \\
0.892\end{array}$ & $\begin{array}{l}3.084 \\
0.749\end{array}$ \\
\hline
\end{tabular}


In Table 3, the first column shows the relationships between belief in rumors and the other variables in this study. Belief in rumors has a statistically significant positive relationship with the perceived risk of the Fukushima accident. Among the coefficients in the second column, belief in rumors has the largest correlation coefficient with the Fukushima accident, implying that the disaster is a critical event that reinforced this belief.

For the communication variables, belief in rumors demonstrated a negative relationship with source credibility and a positive relationship with quantity of information, usefulness of information, and the receiver's involvement and ability. Source credibility has the largest coefficient. However, the receiver's involvement and ability demonstrated a very weak relationship with belief in rumors. These findings imply that source credibility is more important than that of the receiver, as confirmed by Ryu and Kim [50]. Source credibility has a negative impact on belief in rumors, which indicates that if respondents trust those who provide the information, they tend to not believe rumors.

Noteworthy is the negative relationship between quantity of information and belief in rumors, because generally, more information eliminates suspicion of facts. Findings did not confirm our hypothesized direction of relationships. This negative relationship may be attributed to the content of the information. When the Fukushima accident occurred, more negative than positive information was disseminated worldwide. Such negative information might facilitate belief in rumors.

The usefulness of information, in other words, the qualitative aspect, is positively related to belief in rumors. This implies that when a disaster occurs, the usefulness of information increases negative biases and rumors about the event. It is noticeable that the quantity of information has a larger coefficient with belief in rumor than does the qualitative usefulness attributes of information.

We expected a negative relationship between the receiver's involvement and belief in rumors, as previous research [34] indicated that when people perceive high personal relevance with a message, they judge it with more scrutiny. Scrutiny filters unconfirmed information, in this case, the rumors related to the Fukushima accident. However, the correlation coefficients contrast with the expectation, indicating a positive relationship between involvement and belief in rumors. Possibly, this result reflects that people's interests and orientations in the case of the Fukushima accident are usually negatively oriented, because a negative climate dominates this situation at the time.

Ability demonstrated a positive relationship with belief in rumors. While we expected a cognitive check based on ability, the results indicated a different role. Confidence in one's competence seems to increase the biased adoption of unverified rumors.

For variables of the psychometric paradigm, perceived risk and emotion have a positive relationship with belief in rumors, while perceived benefits, trust, and knowledge showed a negative relationship. The direction of association follows the prediction in Hypothesis 2, implying that the psychometric variables may be better reliable measures to predict belief in rumors than the communication factors. Moreover, excepting knowledge, the correlation coefficients for all variables in the psychometric paradigm are similar $(-0.322,0.367,-0.316$, and 0.333$)$.

Across the psychometric and communication factors, perceived risk has the largest coefficient with belief in rumors, followed by emotion and trust. These results indicate that the psychometric variables more effectively explain belief in rumors than the communication variables.

Next, we examined the causal impact of the three factors on belief in rumors through a regression analysis. Table 4 provides the results of the regression analysis. The dependent variable was the degree of belief in rumors, and there were 15 independent variables. To determine the effect of three factors, we controlled for gender, age, education, and household income. 
Table 4. Regression analysis.

\begin{tabular}{|c|c|c|c|c|c|c|}
\hline & & B & S.E. & Beta & T-Value & Sig. \\
\hline \multirow{5}{*}{$\begin{array}{l}\text { Socio-demographic } \\
\text { Factors (F1) }\end{array}$} & constant & $3.900 * * *$ & 0.979 & & 3.982 & 0.000 \\
\hline & Age & $-0.012 *$ & 0.007 & -0.043 & -1.835 & 0.067 \\
\hline & Gender (female) & $0.808^{* * *}$ & 0.164 & 0.110 & 4.938 & 0.000 \\
\hline & Education level & -0.099 & 0.228 & -0.010 & -0.434 & 0.664 \\
\hline & Household income & $8.865 \times 10^{-5}$ & 0.000 & 0.018 & 0.869 & 0.385 \\
\hline \multirow{5}{*}{$\begin{array}{l}\text { Communication } \\
\text { Factors (F2) }\end{array}$} & Source credibility & $-0.372 * *$ & 0.149 & -0.075 & -2.493 & 0.013 \\
\hline & Quantity of information & -0.166 & 0.204 & -0.037 & -0.814 & 0.416 \\
\hline & Usefulness of information & $0.244 *$ & 0.127 & 0.045 & 1.925 & 0.054 \\
\hline & Receiver's involvement & 0.131 & 0.109 & 0.029 & 1.195 & 0.232 \\
\hline & Receiver's ability & $0.209 *$ & 0.107 & 0.049 & 1.960 & 0.050 \\
\hline \multirow{5}{*}{$\begin{array}{l}\text { Psychometric } \\
\text { Factors (F3) }\end{array}$} & Perceived benefit & $-0.429 * * *$ & 0.108 & -0.105 & -3.986 & 0.000 \\
\hline & Perceived risk & $0.618^{* * *}$ & 0.117 & 0.132 & 5.271 & 0.000 \\
\hline & Trust & $-0.272 * * *$ & 0.106 & -0.079 & -2.570 & 0.010 \\
\hline & Knowledge & $-0.259 * * *$ & 0.101 & -0.063 & -2.565 & 0.010 \\
\hline & Emotion & $0.442 *$ & 0.241 & 0.090 & 1.829 & 0.068 \\
\hline \multicolumn{2}{|c|}{ Risk perception of the Fukushima accident (F4) } & $1.148^{* * *}$ & 0.095 & 0.282 & 12.067 & 0.000 \\
\hline \multicolumn{2}{|c|}{ F-Value $/ R^{2} /$ Ad. $R^{2}$} & \multicolumn{5}{|c|}{$45.698^{* * * / 0.306 / 0.299}$} \\
\hline $\mathrm{F} 1$ & F-Value/R ${ }^{2} /$ Ad. $R^{2}$ & \multicolumn{5}{|c|}{$19.992 * * * / 0.049 / 0.046$} \\
\hline F2 & F-Value $/ R^{2} /$ Ad. $R^{2}$ & \multicolumn{5}{|c|}{$48.081^{* * *} / 0.133 / 0.130$} \\
\hline F3 & F-Value $/ R^{2} /$ Ad. $R^{2}$ & \multicolumn{5}{|c|}{$81.988^{* * * / 0.207 / 0.205}$} \\
\hline F4 & F-Value $/ R^{2} /$ Ad. $R^{2}$ & \multicolumn{5}{|c|}{$315.736^{* * *} / 0.167 / 0.167$} \\
\hline
\end{tabular}

Note: ${ }^{*}<0.1,{ }^{* *}<0.05,{ }^{* * *}<0.001$.

The results indicate that gender and age take a contrasting role in belief in rumors: gender (female) increases belief in rumors, while a higher age decreases it. In risk studies, since females are considered more vulnerable to risk than males, they generally demonstrate a more risk-averse attitude. Based on a meta-analysis, Byrnes et al. [51] reported that males tend to take more risks. Regarding the effect of age, in the field of conspiracy theory, Goertzel [52] showed that young people were slightly more likely to believe in conspiracies. Therefore, a reasonable hypothesis is that females and younger people are more likely to express a strong belief in rumors. Our data support this hypothesis.

Furthermore, education decreases belief in rumors, because it elicits a more logical review of these rumors. Pasek et al. [53] showed that education significantly decreases misbelief in fact. Among individuals who graduated from college, $11.8 \%$ asserted that Mr. Obama was born abroad and $84.5 \%$ that he was born in the United States. Conversely, more than one-third of the individuals who did not graduate from high school did not believe Mr. Obama was born in the United States (35.4\%). These differences were statistically significant $(p<0.0012)$.

For the communication factors, higher source credibility lowers belief in rumors. Our study measured source credibility in terms of the general positive attributes of a source, namely that the source is trustworthy, exact, fact-based, fair, valid, and considered an expert. As such, even when a negative accident occurs, belief in rumors decreases when people trust in and consider the source positively.

The quantity of negative information was not significant, although the usefulness of information, a qualitative attribute, appears significant, discounting the amount of information. However, Allport and Postman [13] contested this result, arguing that the quantity of negative information facilitates belief in rumor.

The usefulness of information increases belief in rumors. We hypothesized that the usefulness of information in terms of receivers would decrease belief in rumors. However, our results differed from our expectations. When an accident occurs, the usefulness of information tends to exacerbate, not buffer, the spread of negative rumor. As such, the usefulness of information did not seem to filter false information. 
Among the receiver variables, personal involvement did not have a significant effect on belief in rumors, while the receiver's ability increased belief in rumors. Involvement and ability are assumed to filter unconfirmed information, shrinking the power of rumors. However, our results reject this hypothesis. The role of ability differed from what we expected. Such a result might be due to the fact that we focused on measuring respondents' ability to transmit information, not to screen it. The ability to transmit information is neutral, because it does not imply screening inaccurate information, but transferring it. The reduced cognitive ability required for transmission in measurement seems to increase belief in rumors.

Among the variables in the psychometric paradigm, perceived risk and emotion pertaining to nuclear power increase belief in rumors, whereas perceived benefit, trust, and knowledge decrease it.

First, we assumed that perceived risk and benefit would have contrasting effects on belief in rumors. The former may amplify rumors while the latter may discount their negative effect. Our results confirm this contrasting role. In addition, the beta coefficient of each psychometric variable indicates that the largest variance of belief in rumor is explained by perceived risk, followed by perceived benefit. Perceived risk and benefit are the main variables to explain belief in rumor.

Second, trust in government decreased belief in rumors. Today, the public tends to regard the government as an actor involved in conspiracies under the bureaucratic tent. The public's suspicion of government reflects a low level of trust. Research by Goertzel [52] shows significant correlation $(r=-0.37)$ between belief in conspiracies and trust. On the other hand, higher trust decreases the public's suspicion. Our results demonstrated the positive role of trust in belief in rumors.

Third, we hypothesized that knowledge decreases belief in rumors, because it corrects false or inaccurate beliefs. Our data confirmed this hypothesis. However, note that of the five psychometric variables, knowledge has the lowest beta coefficient value. This indicates that when rumors spread, emphasizing objective scientific facts is not the most effective strategy to reduce belief, despite our expectations.

Fourth, the analysis confirmed that a negative stigma increases belief in rumors. Stigma represents a negative affective feeling. Rumors spread easily in situations characterized by anxiety and ambiguity. Rosnow et al. [54] (p. 587) defined anxiety as a negative affective state produced by apprehension about an impending, potentially negative situation. The Fukushima accident seemed to instigate negative anxiety, reinforcing the negative stigma toward nuclear power and strengthening belief in rumors.

Finally, the fear of the Fukushima accident had a significant effect on belief in rumor. Of note is that both the generally perceived risk of nuclear energy in psychometric factor and the specific perceived risk of the Fukushima accident explain large variance in belief in rumors. This implies that besides existing perceived risk about nuclear energy, the Fukushima accident was a powerful event that greatly affected people's distrust and dread. The remarkable explanatory power of the Fukushima accident is observed in the standardized coefficients. As such, risk perception of the Fukushima accident is the most powerful variable in explaining the variance in belief in rumors, followed by perceived risk and benefit, gender, and emotion.

To determine the explanatory power of four factors, we regressed each factor on belief in rumor. The F-value and F-Value, $R^{2}$, and Adjusted $R^{2}$ appear in the last four rows in Table 4 . The data indicate that psychometric factors (F3) explain $20.7 \%$ of the variance, and the Fukushima accident $16.7 \%$. Considering that the former comprises numerous variables and the latter constitutes one variable, the risk perception of Fukushima greatly influenced belief in rumors. Sociodemographic and communication factors have little explanation power.

Besides the direct effect of risk perception of Fukushima accident on belief in rumor, does this risk perception influence the relationships between psychometric variable and belief in rumor?

To determine the moderating effect of risk perception of the Fukushima accident, we input the interaction terms (i.e., each psychometric variable multiplied by the moderator, or the perceived risk of the Fukushima accident) into the existing model. To confirm the moderating effect, we followed the procedure suggested by Baron and Kenny [55]. 
As shown in the Appendix A, five moderating terms were statistically significant. The original relationships remained stable after adding the interaction terms. We also executed a simple slope test to determine whether risk perception of the Fukushima accident had a significant role as moderator when it had a low, medium, or high value (see the Appendix A). The moderating effect is depicted in Figures 1-5, in which the X-axis represents the five independent variables and the Y-axis belief in rumors.

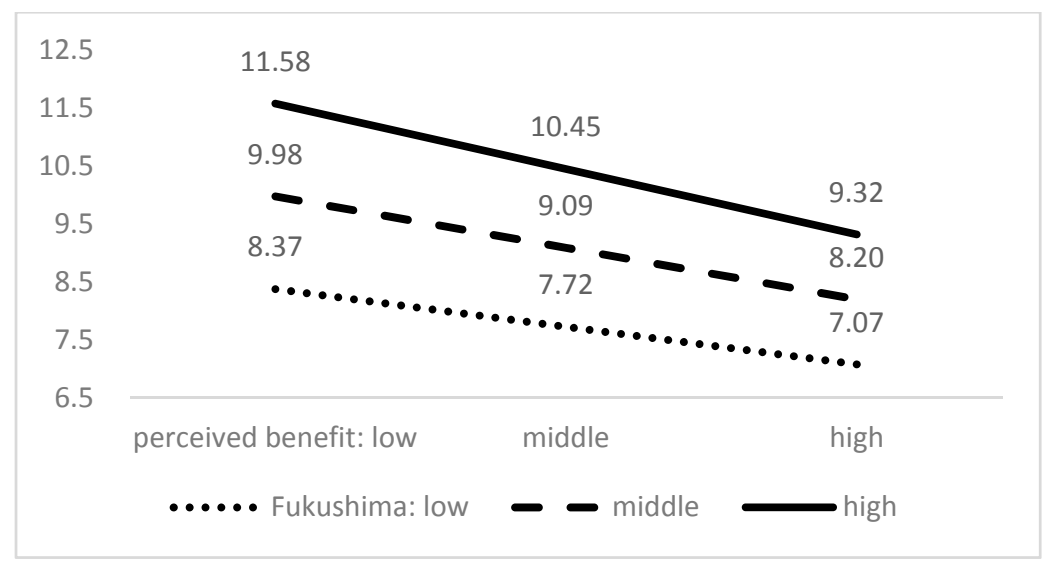

Figure 1. Perceived benefit $(\mathrm{IV}) \times$ Fukushima accident $(\mathrm{M})=$ Belief in rumor (DV). Note: IV (independent variable), M (moderator), DV (dependent variable).

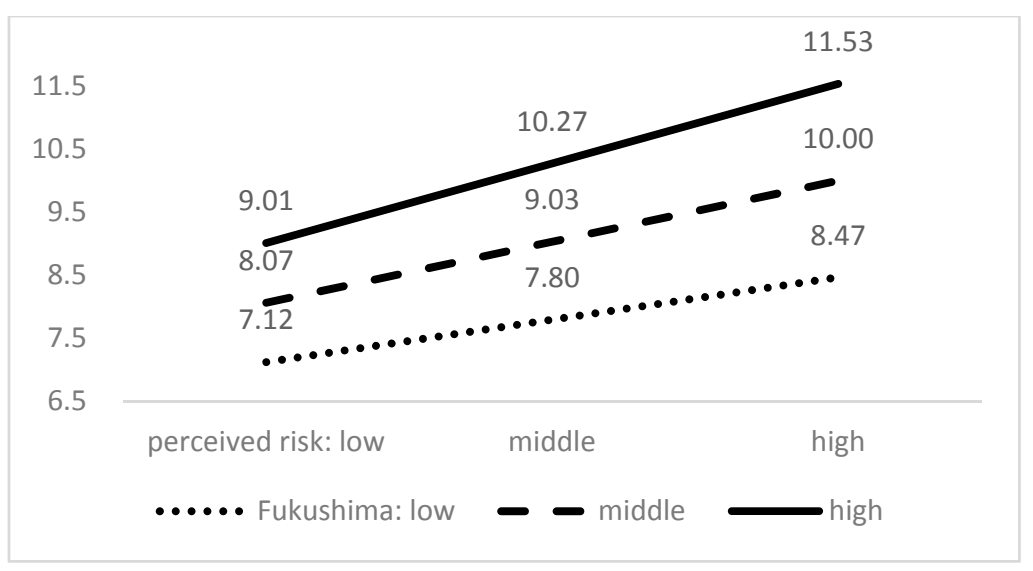

Figure 2. Perceived risk (IV) $\times$ Fukushima accident $(M)=$ Belief in rumor $(D V)$.

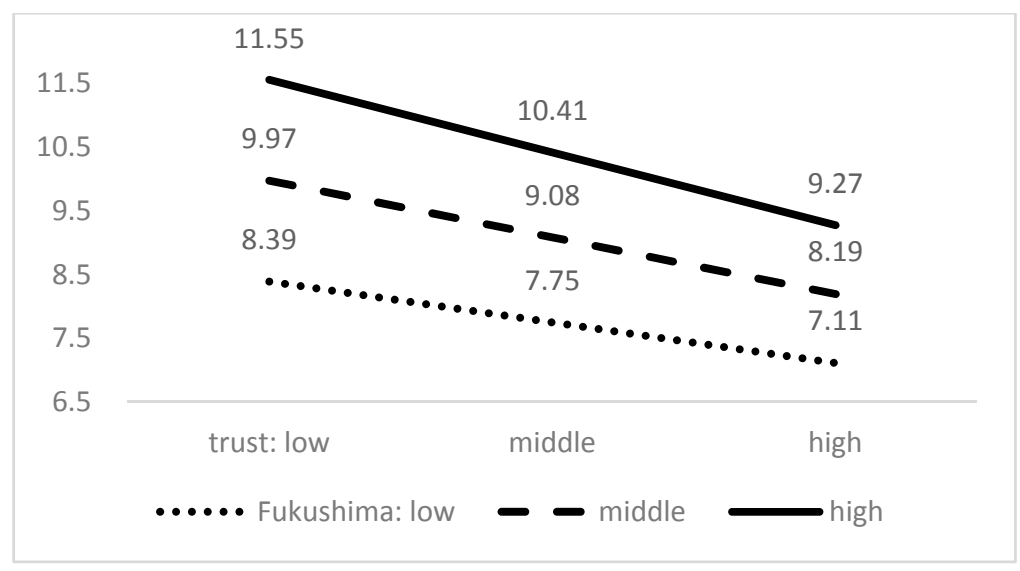

Figure 3. Trust $(\mathrm{IV}) \times$ Fukushima accident $(\mathrm{M})=$ Belief in rumor $(\mathrm{DV})$. 


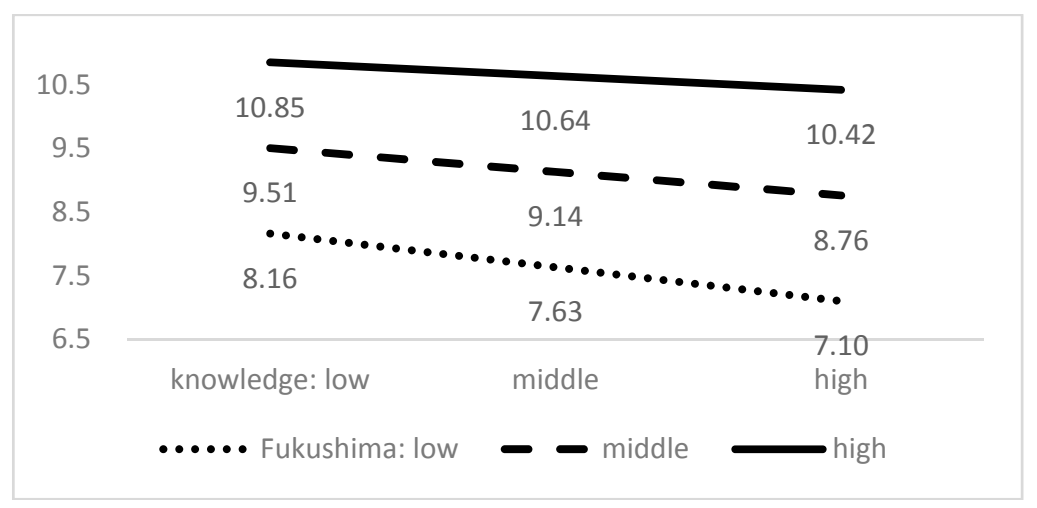

Figure 4. Knowledge $(\mathrm{IV}) \times$ Fukushima accident $(\mathrm{M})=$ Belief in rumor $(\mathrm{DV})$.

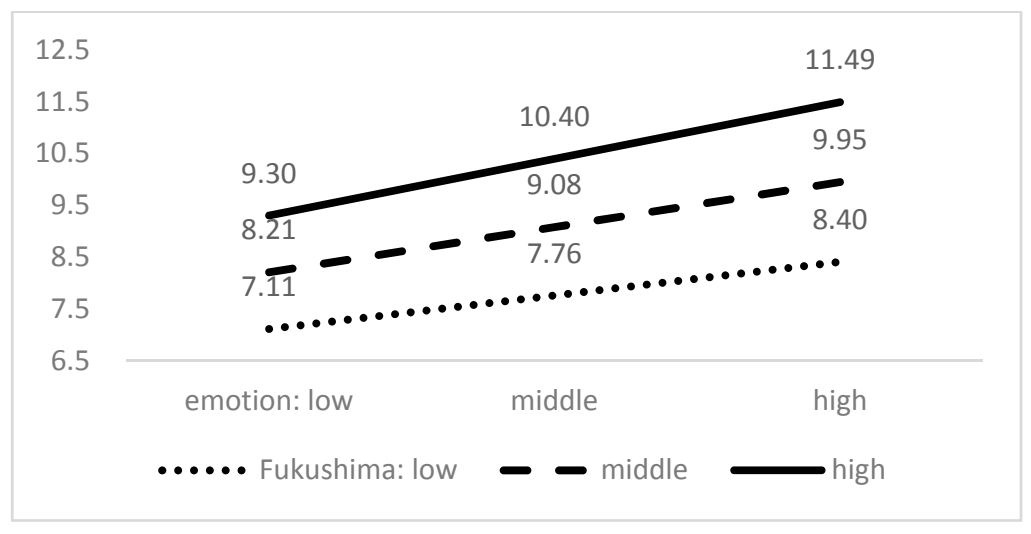

Figure 5. Emotion $(\mathrm{IV}) \times$ Fukushima accident $(\mathrm{M})=$ Belief in rumor $(\mathrm{DV})$.

Figure 1 shows that perceived benefit reduces belief in rumors. However, this effect depends on the perceived risk of the Fukushima nuclear accident, which weakens the power of perceived benefit to decrease belief in rumors. Figure 2 indicates that perceived risk generally increases belief in rumors. This effect is facilitated when the perceived risk of the Fukushima accident is higher. Notably, general perceived risk is reinforced by specific perceived risk. Figure 3 demonstrates the moderating effect of perceived risk of the Fukushima accident on the relationship between trust and belief in rumors. Trust decreases belief in rumors more rapidly when the perceived risk increases. Thus, the negative relationship between trust and belief in rumors is strong when the perceived risk of the Fukushima accident is higher. This indicates that trust is an important positive factor that blocks the diffusion of unfiltered false information. Figure 4 shows the moderating effect of the Fukushima accident on the relationship between knowledge and belief in rumors. More knowledge usually reduces belief in rumors. This effect is facilitated when the level of perceived risk of the Fukushima accident is lower. Figure 5 demonstrates that higher emotion increases belief in rumors when perceived risk of the Fukushima accident is higher. Thus, the positive relationship between emotion and belief in rumors is stronger when the perceived risk of the Fukushima accident is higher.

In short, higher risk perception of the Fukushima accident facilitates the effects of perceived risk, trust, and emotion on belief in rumors and buffers the effect of knowledge.

\section{Results and Discussion}

Our analysis examined the role of three factors that influence belief in rumors. In particular, we compared the effect of risk perception of Fukushima accident with that of the variables constituting two factors-the psychometric paradigm and communication. In risk studies, the psychometric paradigm focuses on perceived benefit, perceived risk, trust, stigma, and knowledge. On the other 
hand, the communication model focuses on source credibility, the quantity/usefulness of information, and the receiver's involvement and ability. Since these two models have mainly explained the variance in risk judgement and process, it is meaningful to examine the effect of risk perception of the Fukushima accident on belief in rumors when controlling for these factors. Second, to know the effect of the Fukushima accident, we explored its moderating role in the relationship between psychometric paradigm and belief in rumors. Results showed that Hypotheses 1 and 3 are fully supported and Hypothesis 2 is partially confirmed. Next, we summarize and describe the implications of our findings.

First, among the sociodemographic variables, gender (female) increases belief in rumors, whereas age (older) decreases it. As females tend to be risk-averse, they have a higher risk perception, which may influence respondents' dependence on rumors. Because younger people are likely to believe in unconfirmed stories such as conspiracy theories, they have a stronger belief in rumors than older people. However, few studies examine the effects of gender and age in rumor studies, and therefore, such interpretations need more validation in the future.

Second, the communication factors partially support Hypothesis 1 . Higher source credibility lowers belief in rumors. Of the communication variables, source credibility has the largest beta coefficient value, indicating that trust in those who deliver information on nuclear power plays a critical role in determining the belief in rumors. This means that source credibility is best instrument to reduce belief in rumor.

Next, the quantity of information was not significant, although the usefulness of information had a significant effect. These results imply that the quantity of information is not as important as qualitative attributes in terms of belief in rumors. Moreover, the receiver's high ability, not personal involvement, decreases belief in rumors. This is in contrast to our hypothesis. These results may reflect our measures, which focus only on ability of transmission. Moreover, such results might have come from both varieties of sources and complex reality of community, which cannot be explained by a simple mechanistic model. Therefore, it needs the advanced communication model beyond Kasperson's simple model. Today, new social media creates a new environment that people have never experienced. As social media becomes a major force that changes reality, the influence of tradition media is gradually disappearing. Social construction by media changed the reality. Recently, several theoretical models were invented to explain the more interactive and dynamic communication under the new environment of internet or social media. According to Situational Crisis Communication Theory (SCCT, by Liu et al. [56]) or Networked Crisis Communication Model (NCCM, by Schultz, Utz, and Glocka [57]), social media creators did not simply forward the messages from traditional media but create and spread their own versions of the crisis. Moreover, the Social-Mediated Crisis Communication (SMCC) model explains how organizations may best communicate with public as well as how public transmits information during crises [58].

During the Fukushima disaster, social media produced a lot of information. Friedman [59] showed that the Internet made an enormous amount of information on Fukushima available, far more than was provided by the media during the Three Mile Island and Chernobyl accidents. Moreover, citizens actively participated in blogs and on Facebook, Twitter, and YouTube, exchanging views and directing others to important news articles or videos. Based on network analysis of over 300 million tweets after the 2011 Japan earthquake, Toriumi et al. [60] found an abrupt increase in degree distribution of information by Twitter directly after the earthquake. Moreover, based on media system dependency theory, Jung [61] surveyed Japanese university students after the Fukushima accident. This study showed that the use and type of social media influenced people's attitude toward the Fukushima accident. However, authorities' communication strategies did not follow up such trends of social media. Ng and Lean [62] argued that amid the clear crisis of Fukushima, the potential of social media was not fully tapped. This resulted in undue stress and distrust of authorities, in particular, altering the level of trust in them.

Third, the psychometric paradigm fully supports Hypothesis 2 . All the psychometric variables have significant impacts on belief in rumors. As such, perceived benefit, trust, and knowledge 
decrease belief in rumors, and perceived risk and stigma increase it. Of the five psychometric variables, perceived risk is the most powerful explanatory factor to predict belief in rumors, followed by perceived benefit, trust, knowledge, and emotion. Alhakami and Slovic [63] reported a robust inverse relationship between perceived risk and benefit. The correlation efficient in our analysis confirms this inverse relationship $\left(-0.34^{* * *}\right)$. Those findings proposed that to reduce rumor, researchers and the government should focus on strategies to enhance perceived benefit and reduce perceived risk.

Fourth, our analysis revealed a significant impact of risk perception of the Fukushima accident on belief in rumors. Here, perceived risk positively influenced belief in rumors. This effect emerged when controlling for other perception and communication factors. Furthermore, the standardized beta coefficient of perceived risk of the Fukushima accident is the largest among the independent variables. This indicates that the Fukushima accident is a pivotal event that negatively influences people's perceptions of nuclear power energy and belief in rumors. When an unprecedented disaster occurs, unconfirmed rumors are usually diffused and consumed. Our findings confirmed the theoretical argument of DiFonzo and Bordia [11] (p. 203) that rumors arise from ambiguous, threatening, or potentially threatening situational contexts in which people feel a psychological need for understanding or security.

Finally, we confirmed the moderating effect of risk perception of the Fukushima accident on the relationships between psychometric variables and belief in rumors. We analyzed these relationships, because no other studies have investigated the moderating role of risk perception of the Fukushima accident. We found that a higher perceived risk of the Fukushima accident facilitated the effect of perceived risk, perceived benefit, trust, and emotion on belief in rumors, and buffered the negative impact of knowledge. Moreover, perceived risk and emotion increased belief in rumors when the perceived risk of Fukushima accident was considered, but perceived benefit and trust decreased when the perceived risk entered the equation.

Today, all of the risk communication theories and models are evolving because of rapid and profound changes in the communication environment. Old, simple model cannot explain the present complex reality of communication. If possible, we expected that our findings contribute to clarifying the theoretical or practical issue of communicaiton today. Our research suggests that belief in rumors increases when an external social event such as the Fukushima accident and the internal mindset such as the structure of perception are combined. The shift in belief in rumors originates in everyday perception and depends on an unprecedented disaster. Therefore, we need more elaborate strategies to eliminate rumors. DiFonzo et al. [12] proposed strategies for preventing and neutralizing rumors. Preventing rumors entails reducing their generation, credulity, and dissemination, while neutralizing them entails ignoring, confirming, commenting on, or refuting rumors. Our findings provide insight into neutralizing rumors, decreasing perceived risk and negative information, and increasing source credibility, perceived benefit, trust, and knowledge.

Our results lead to several practical strategies for managing rumors, aimed at reducing belief in rumor through effective formal communications and increased certainty of information. To achieve more effective communication, the information needs enhanced source credibility and trust, the role of which we confirmed in the context of the Fukushima accident. For effective communication, the WHO outbreak communication guidelines stressed five key points in crisis outbreak: (1) build, maintain, or restore trust; (2) announce early; (3) be transparent; (4) understand the public; and (5) incorporate risk communication into preparedness planning. All of these require the authorities' effort and action for speedy implementation.

Acknowledgments: This research was conducted without any research grants.

Author Contributions: Two authors contributed equally to this work.

Conflicts of Interest: The authors declare no conflict of interest. 


\section{Appendix A}

Table A1. Analysis of Interaction Effect and Simple Slop Test.

\begin{tabular}{|c|c|c|c|c|c|c|c|c|c|c|c|c|c|}
\hline \multicolumn{7}{|c|}{ Fukushima $*$ P. Benefit $=$ Belief in Rumor } & \multicolumn{7}{|c|}{ P. Fukushima ${ }^{*}$ P. Risk = Belief in Rumor } \\
\hline & B & SE & Beta & B & SE & Beta & & B & SE & Beta & B & SE & Beta \\
\hline P. Fukushima & $1.48^{* * *}$ & 0.092 & 0.363 & $1.507^{* * *}$ & 0.092 & 0.37 & P. Fukushima & $1.317^{* * *}$ & 0.096 & 0.323 & $1.368^{* * *}$ & 0.096 & 0.336 \\
\hline P. Benefit & $-1.055^{* * *}$ & 0.092 & -0.258 & $-0.99^{* * *}$ & 0.094 & -0.242 & P. Risk & $1.22^{* * *}$ & 0.11 & 0.261 & $1.229^{* * *}$ & 0.109 & 0.263 \\
\hline Interaction Term & & & & $-0.295^{* * *}$ & 0.098 & -0.068 & Interaction Term & & & & $0.414^{* * *}$ & 0.1 & 0.093 \\
\hline F-value & \multicolumn{3}{|c|}{$236.522 * * *$} & \multicolumn{3}{|c|}{$161.495^{* * *}$} & F-value & \multicolumn{3}{|c|}{$231.723 * * *$} & \multicolumn{3}{|c|}{$161.820 * * *$} \\
\hline $\mathrm{R}^{2}$ & \multicolumn{3}{|c|}{0.232} & \multicolumn{3}{|c|}{0.236} & $\mathrm{R}^{2}$ & \multicolumn{3}{|c|}{0.228} & \multicolumn{3}{|c|}{0.236} \\
\hline $\mathrm{R}^{2}$ Change & \multicolumn{3}{|c|}{0.231} & \multicolumn{3}{|c|}{0.235} & $\mathrm{R}^{2}$ Change & \multicolumn{3}{|c|}{0.227} & \multicolumn{3}{|c|}{0.235} \\
\hline \multirow{3}{*}{ Simple Slope Test } & Low & \multirow{2}{*}{\multicolumn{5}{|c|}{$\begin{array}{c}\mathrm{B}=-0.723^{* * *} \mathrm{se}=0.144 \mathrm{t}=-5.038 \\
\mathrm{~B}=-0.99^{* * *} \mathrm{se}=0.130 \mathrm{t}=-7.592\end{array}$}} & \multirow{3}{*}{ Simple Slope Test } & Low & \multirow{2}{*}{\multicolumn{5}{|c|}{$\begin{array}{l}\mathrm{B}=0.855^{* * *} \mathrm{se}=0.140 \mathrm{t}=6.085 \\
\mathrm{~B}=1.229^{* * *} \mathrm{se}=0.140 \mathrm{t}=8.773\end{array}$}} \\
\hline & Middle & & & & & & & Middle & & & & & \\
\hline & High & \multicolumn{5}{|c|}{$\mathrm{B}=-1.257^{* * *} \mathrm{se}=0.114 \mathrm{t}=-11.038$} & & High & \multicolumn{5}{|c|}{$\mathrm{B}=1.603^{* * *} \mathrm{se}=0.0143 \mathrm{t}=11.194$} \\
\hline Effect Size & \multicolumn{6}{|c|}{0.012} & Effect Size & \multicolumn{6}{|c|}{0.02} \\
\hline \multicolumn{7}{|c|}{ P. Fukushima ${ }^{*}$ Trust $=$ Belief in Rumor } & \multicolumn{7}{|c|}{ P. Fukushima ${ }^{*}$ Knowledge $=$ Belief in Rumor } \\
\hline & B & SE & Beta & B & SE & Beta & & B & SE & Beta & B & SE & Beta \\
\hline P. Fukushima & $1.474^{* * *}$ & 0.092 & 0.362 & $1.473^{* * *}$ & 0.092 & 0.362 & P. Fukushima & $1.652^{* * *}$ & 0.093 & 0.406 & $1.661^{* * *}$ & 0.093 & 0.408 \\
\hline Trust & $-0.852^{* * *}$ & 0.078 & -0.246 & $-0.836^{* * *}$ & 0.078 & -0.242 & Knowledge & $-0.41^{* * *}$ & 0.095 & -0.099 & $-0.418^{* * *}$ & 0.095 & -0.101 \\
\hline Interaction Term & & & & $-0.261^{* * *}$ & 0.082 & -0.071 & Interaction Term & & & & $0.196^{*}$ & 0.103 & 0.044 \\
\hline F-value & & $97^{* * *}$ & & & $36^{* * *}$ & & F-value & & $.071^{* * *}$ & & & $17^{* * *}$ & \\
\hline $\mathrm{R}^{2}$ & & & & & & & $\mathrm{R}^{2}$ & & .177 & & & 79 & \\
\hline $\mathrm{R}^{2}$ Change & & & & & 29 & & $\mathrm{R}^{2}$ Change & & .176 & & & 78 & \\
\hline & Low & & $3=-0.60$ & *** se $=0.111$ & $=-5.41$ & & & Low & & $\mathrm{B}=-0.5 \mathrm{c}$ & $* *$ se $=0.13$ & $=-4.39$ & \\
\hline Simple Slope Test & Middle & & $B=-0.83$ & $* * * \mathrm{se}=0.095$ & $=-8.81$ & & Simple Slope Test & Middle & & $\mathrm{B}=-0.41$ & $* *$ se $=0.11$ & $=-3.64$ & \\
\hline & High & & $3=-1.07$ & *** se $=0.104$ & $=-1.30$ & & & High & & $\mathrm{B}=-0.2$ & ${ }^{*} \mathrm{se}=0.13 \mathrm{C}$ & -1.857 & \\
\hline Effect Size & & & 0.0 & & & & Effect Size & & & & & & \\
\hline & Fukushima & motion & $=$ Belief & Rumor & & & & & & & & & \\
\hline & B & SE & Beta & B & SE & Beta & & & & & & & \\
\hline P. Fukushima & $1.424^{* * *}$ & 0.093 & 0.35 & $1.459^{* * *}$ & 0.094 & 0.358 & & & & & & & \\
\hline Emotion & $1.223^{* * *}$ & 0.113 & 0.249 & $1.163^{* * *}$ & 0.114 & 0.236 & & & & & & & \\
\hline Interaction Term & & & & $0.33^{* * *}$ & 0.112 & 0.067 & & & & & & & \\
\hline F-value & & $52 * * *$ & & & $56^{* * *}$ & & & & & & & & \\
\hline $\mathrm{R}^{2}$ & & & & & & & & & & & & & \\
\hline $\mathrm{R}^{2}$ Change & & & & & 29 & & & & & & & & \\
\hline & Low & & $\mathrm{B}=0.86$ & *** se $=0.165$ & $=5.225$ & & & & & & & & \\
\hline Simple Slope Test & Middle & & $\mathrm{B}=1.16$ & $* * *$ se $=0.136$ & $=8.570$ & & & & & & & & \\
\hline & High & & $\mathrm{B}=1.46$ & *** se $=0.138$ & $=1.571$ & & & & & & & & \\
\hline Effect Size & & & 0.0 & & & & & & & & & & \\
\hline
\end{tabular}




\section{References}

1. Kim, Y.; Kim, M.; Kim, W. Effect of the Fukushima nuclear disaster on global public acceptance of nuclear energy. Energy Policy 2013, 61, 822-828. [CrossRef]

2. Huang, L.; Zhou, Y.; Han, Y.; Hammitt, J.K.; Bi, J.; Yang, L. Effect of the Fukushima nuclear accident on the risk perception of residents near a nuclear power plant in China. Proc. Natl. Acad. Sci. USA 2013, 110, 19742-19747. [CrossRef] [PubMed]

3. Tsujikawa, N.; Tsuchida, S.; Shiotani, T. Changes in the factors influencing public acceptance of nuclear power generation in Japan since the 2011 Fukushima Daiichi nuclear disaster. Risk Anal. 2016, 36, 98-113. [CrossRef] [PubMed]

4. Visschers, V.H.; Siegrist, M. How a nuclear power plant accident influences acceptance of nuclear power: Results of a longitudinal study before and after the Fukushima disaster. Risk Anal. 2013, 33, 333-347. [CrossRef] [PubMed]

5. Kawasaki, A.; Meguro, K.; Hener, M. Comparing the disaster information gathering behavior and post-disaster actions of Japanese and foreigners in the Kanto area after the 2011 Tohoku Earthquake. In Proceedings of the 2012 WCEE, Lisbon, Portugal, 24-28 September 2012; Available online: http: //www.iitk.ac.in/nicee/wcee/article/WCEE2012_2649.pdf (accessed on 21 November 2017).

6. Ozeki, Y. The Risks of Web Media, as Shown by Disaster. Available online: http://astand.asahi.com/ magazine/wrnational/2011042000017.html (accessed on 18 October 2011). (In Japanese)

7. The Asahi Shimbun. TEPCO: Radioactive Substances Belong to Landowners, Not Us. The Asahi Shimbun, 24 November 2011. Available online: http:/ /ajw.asahi.com/article/behind_news/social_affairs/ AJ201111240030 (accessed on 26 November 2017).

8. Jacob, B.; Mawson, A.R.; Payton, M.; Guignard, J.C. Disaster Mythology and Fact: Hurricane Katrina and Social Attachment. Public Health Rep. 2008, 123, 555-566. [CrossRef] [PubMed]

9. Knapp, A. Psychology of Rumor. Public Opin. Q. 1944, 8, 22-37. [CrossRef]

10. Available online: http:// news.chosun.com (accessed on 31 July 2013).

11. DiFonzo, N.; Bordia, P. Rumor Psychology: Social and Organizational Approaches; American Psychological Association: Washington, DC, USA, 2007.

12. DiFonzo, N.; Bordia, P.; Rosnow, R.L. Reining in rumors. Organ. Dyn. 1994, 23, 47-62. [CrossRef]

13. Allport, G.W.; Postman, L.J. An analysis of rumor. Public Opin. Q. 1947, 10, 501-517. [CrossRef]

14. Allport, G.W.; Postman, L.J. The Psychology of Rumor; Holt, Rinehart \& Winston: New York, NY, USA, 1947.

15. Rosnow, R.L. Inside Rumor: A Personal Journey. Am. Psychol. 1991, 46, 484-496. [CrossRef]

16. Difonzo, N.; Bordia, P. Rumor, gossip and urban legends. Diogenes 2007, 54, 19-35. [CrossRef]

17. Slovic, P. The Perception of Risk; Routledge: London, UK, 2016.

18. Fischhoff, B.; Slovic, P.; Lichtenstein, S.; Read, S.; Combs, B. How safe is safe enough? A psychometric study of attitudes towards technological risks and benefits. Policy Sci. 1978, 9, 127-152. [CrossRef]

19. Slovic, P.; Fischhoff, B.; Lichtenstein, S. Characterizing perceived risk. In Perilous Progress: Managing the Hazarak of Technology; Kates, R.W., Hohenemser, C., Kasperson, J.X., Eds.; Westview Press: Boulder, CO, USA, 1985.

20. Wildavsky, A. A cultural theory of responsibility. In Bureaucracy and Public Choice; Lane, J., Ed.; Sage: London, UK, 1987.

21. Gaskell, G.; Allum, N.; Wagner, W.; Kronberger, N.; Torgersen, H.; Hampel, J. GM foods and the misperception of risk perception. Risk Anal. 2004, 24, 185-194. [CrossRef] [PubMed]

22. Cobb, M.D.; Macoubrie, J. Public perceptions about nanotechnology: Risks, benefits and trust. J. Nanopart. Res. 2004, 6, 395-405. [CrossRef]

23. Renn, O. Risk communication: Towards a rational discourse with the public. J. Hazard. Mater. 1992, 29, 465-519. [CrossRef]

24. Shannon, C.E.; Weaver, W. The Mathematical Theory of Communication; The University of Illinois Press: Urbana, IL, USA, 1949.

25. Kasperson, R.E.; Renn, O.; Slovic, P.; Brown, H.S.; Emel, J.; Goble, R.; Ratick, S. The social amplification of risk: A conceptual framework. Risk Anal. 1988, 8, 177-187. [CrossRef] 
26. Kim, S.; Lim, C.; Jeong, J.; Wang, J.; Park, C. Analyzing the risk judgement about Fukushima nuclear accident and nuclear power by integrating the risk-perception paradigm with risk communication model. Korea Public Adm. J. 2014, 23, 113-144.

27. Trumbo, C.W.; McComas, K.A. The Function of credibility in information processing for risk perception. Risk Anal. 2003, 23, 343-353. [CrossRef] [PubMed]

28. Porter, E.G. Birth control discontinuance as a diffusion process. Stud. Fam. Plan. 1984, 15, 20-29. [CrossRef]

29. Liang, C.; Chou, W.-S.; Hsu, Y.-L. The factors of influencing college student's belief in consumption-type internet rumors. Int. J. Cyber Soc. Educ. 2009, 2, 37-46.

30. Lee, J.; Park, D.H.; Han, I. The effect of negative online consumer reviews on product attitude: An information processing view. Electron. Commer. Res. Appl. 2008, 7, 341-352. [CrossRef]

31. Chen, S.; Chaiken, S. The heuristic-systematic model in its broader context. In Dual-Process Theories in Social Psychology; Chaiken, S., Trope, Y., Eds.; Guilford Press: New York, NY, USA, 1999; pp. 73-96.

32. Donovan, P. How idle is idle talk? One hundred years of rumor research. Diogenes 2013, 54, 59-82. [CrossRef]

33. Rosnow, R.L.; Kimmel, A.J. Rumor. In Encyclopedia of Psychology; Kazdin, A.E., Ed.; Oxford University Press/American Psychological Association: New York, NY, USA, 2000; Volume 7, pp. 122-123.

34. Petty, R.E.; Cacioppo, J.T. Attitudes and Persuasion: Classic and Contemporary Approaches; WIlliam C. Brown: Dubuque, IA, USA, 1981.

35. Petty, R.E.; Cacioppo, J.T. Issue involvement can increase or decrease persuasion by enhancing message-relevant cognitive responses. J. Pers. Soc. Pschol. 1979, 37, 1915-1926. [CrossRef]

36. Trumbo, C.W. Heuristic-systematic information processing and risk judgment. Risk Anal. 1999, 19, 391-400. [CrossRef] [PubMed]

37. Cacioppo, J.T.; Petty, R.E.; Morris, K.J. Effects of need for cognition on message evaluation, recall, and persuasion. J. Pers. Soc. Psychol. 1983, 45, 805-818. [CrossRef]

38. Kuklinski, J.H.; Metlay, D.S.; Kay, W.D. Citizen knowledge and choices on the complex issue of nuclear energy. AJPS 1982, 26, 615-642. [CrossRef]

39. Brown, J.M.; White, H.M. The public's understanding of radiation and nuclear waste. J. Radiol. Prot. 1987, 7, 61-70. [CrossRef]

40. Dickson, D. The Case for a 'Deficit Model' of Science Communication. 2005. Available online: http:/ / medsci. free.fr/docsderef/Dickson2005_Deficit\%20model\%20of\%20science\%20communication.pdf (accessed on 21 November 2017).

41. Siegrist, M.; Cvetkovich, G. Perception of hazards: The role of social trust and knowledge. Risk Anal. 2000, 20, 713-719. [CrossRef] [PubMed]

42. Slovic, P.; Layman, M.; Kraus, N.; Flynn, J.; Chalmers, J.; Gesell, G. Perceived risk, stigma, and potential economic impacts of a high-level nuclear waste repository in Nevada. Risk Anal. 1991, 11, 683-696. [CrossRef] [PubMed]

43. Peters, E.; Slovic, P. The role of affect and worldviews as orienting dispositions in the perception and acceptance of nuclear Power1. J. Pers. Soc. Psychol. 1996, 26, 1427-1453. [CrossRef]

44. Prasad, J. The psychology of rumor: A study relating to the great Indian earthquake of 1934. Br. J. Psychol. 1935, 41, 129-144.

45. Yamamura, E. Experience of technological and natural disaster and their impact on the perceived risk of nuclear accidents after the Fukushima nuclear disaster in Japan 2011: A cross-country analysis. J. Socio-Econ. 2012, 41, 360-363. [CrossRef]

46. Prati, G.; Bruna Zani, B. The effect of the Fukushima nuclear accident on risk perception, antinuclear behavioral intentions, attitude, trust, environmental beliefs, and values. Environ. Behav. 2012, 45, 782-798. [CrossRef]

47. Eckstein, H. Case studies and theory in political science. In Handbook of Political Science; Greenstein, F., Polsby, N., Eds.; Addison-Wesley: Reading, MA, USA, 1975; Volume 7, pp. 79-138.

48. Yin, R.K. Case Study Research: Design and Methods; Sage Publication: Thusand Oaks, CA, USA; London, UK, 1994.

49. Lijphart, A. Comparative politics and the comparative method. Am. Polit. Sci. Rev. 1971, 65, 682-693. [CrossRef]

50. Ryu, Y.; Kim, S. Testing the heuristic/systematic information-processing model (HSM) on the perception of risk after the Fukushima nuclear accidents. J. Risk Res. 2015, 18, 840-859. [CrossRef] 
51. Byrnes, J.P.; Miller, D.C.; Schafer, W.E. Gender differences in risk taking: A meta-analysis. Psychol. Bull. 1999, 125, 367-383. [CrossRef]

52. Goertzel, T. Belief in Conspiracy Theories. Polit. Psychol. 1994, 15, 733-744. [CrossRef]

53. Pasek, J.; Stark, T.H.; Krosnick, J.A.; Tompson, T. What motivates a conspiracy theory? Birther beliefs, partisanship, liberal-conservative ideology, and anti-black attitudes. Elect. Stud. 2014, 40, 482-489. [CrossRef]

54. Rosnow, R.L. Psychology of rumor reconsidered. Psychol. Bull. 1980, 87, 578-591. [CrossRef]

55. Baron, R.M.; Kenny, D.A. The moderator-Mediator variable distinction in social psychological research: Conceptual, strategic, and statistical considerations. J. Pers. Soc. Psychol. 1986, 51, 1173-1182. [CrossRef] [PubMed]

56. Liu, B.F.; Austin, L.; Jin, Y. How publics respond to crisis communication strategies: The interplay of information form and source. Public Relat. Rev. 2011, 37, 345-353. [CrossRef]

57. Schultz, F.; Utz, S.; Glocka, S. Crisis communication and social media. On the effects of medium, media credibility, crisis type and emotions. In Proceedings of the Etmaal Conference, Leuven, Belgium, 9-10 February 2012.

58. Jin, Y.; Liu, B.F. The blog-mediated crisis communication model: Recommendations for responding to influential external blogs. J. Public Relat. Res. 2010, 22, 429-455. [CrossRef]

59. Friedman, S.M. Three Mile Island, Chernobyl, and Fukushima: An analysis of traditional and new media coverage of nuclear accidents and radiation. Bull. At. Sci. 2011, 67, 55-65. [CrossRef]

60. Toriumi, F.; Sakaki, T.; Shinoda, K.; Kazama, K.; Kurihara, S.; Noda, I. Information Sharing on Twitter during the 2011 Catastrophic Earthquake. In Proceedings of the International World Wide Web Conference Committee (IW3C2), Rio de Janeiro, Brazil, 13-17 May 2013.

61. Jung, J.-Y. Social media use and goals after the Great East Japan Earthquake. First Monday 2012. [CrossRef]

62. $\mathrm{Ng}$, K.; Lean, M. The Fukushima nuclear crisis reemphasizes the need for improved risk communication and better use of social media. Health Phys. 2012, 103, 307-310. [CrossRef] [PubMed]

63. Alhakami, A.S.; Slovic, P. A psychological study of the inverse relationship between perceived risk and perceived benefit. Risk Anal. 1994, 14, 1085-1096. [CrossRef] [PubMed]

(C) 2017 by the authors. Licensee MDPI, Basel, Switzerland. This article is an open access article distributed under the terms and conditions of the Creative Commons Attribution (CC BY) license (http:/ / creativecommons.org/licenses/by/4.0/). 